\title{
A Microleakage Evaluation of Two Generations of Bonding Agents Using a Novel Fluid Filtration Model
}

\author{
Asiya Mujawar ${ }^{1}$, Vivek Hegde ${ }^{2}$, Srilatha Shanmugasundaram ${ }^{3}$
}

\begin{abstract}
Aim: The aim of the study was to evaluate the microleakage between two different generations of bonding agents using fluid filtration model. Materials and methods: In total, 60 human extracted mandibular molars were used in the study. The samples were divided into three groups, group I-Adper Scotchbond primer and adhesive, group II-Single Bond Universal adhesive, and group III—control group. All the samples were restored and stored in distilled water for 24 hours followed by thermocycling in water bath for 1,000 cycles between $5 \pm 2^{\circ} \mathrm{C}$ and $55 \pm 2^{\circ} \mathrm{C}$, for dwell time of 30 seconds and transfer time of 10 seconds. The samples were then tested for leakage under fluid filtration model.

Results: There was a statistically significant difference between the leakage in between the two groups. The difference was found to be statistically significant $(p<0.05)$. Single bond group showed better adhesion and less leakage compared to the Adper Scotchbond primer and adhesive. Conclusion: Single Bond Universal adhesive (3M) showed the least amount of microleakage when compared to Adper Single Bond 2 and Adper Scotchbond primer and adhesive. Fluid filtration model was successfully constructed and worked efficiently and can be considered as one of the ideal methods for evaluation of microleakage.

Keywords: Adper Scotchbond primer and adhesive, Adper Single Bond, Microleakage, Single Bond Universal.

International Journal of Prosthodontics and Restorative Dentistry (2020): 10.5005/jp-journals-10019-1260
\end{abstract}

\section{INTRODUCTION}

A microscopic space always exists between the tooth restoration interface which results into microleakage responsible for breakdown at the marginal area of restoration and development of pulpal pathology that jeopardize the clinical longevity of restoration. The percolation of oral fluid and bacteria along the restoration margins may be responsible for pulpal irritation, recurrent caries, hypersensitivity, and failure of restoration.

The evaluation of dental composite resin restorations over the past 20 years has centered primarily on issues of biomechanics, ${ }^{1-4}$ as these parameters are most immediate in determining short-term clinical restoration success. With advanced technologies, dental adhesives have evolved from no-etch to total-etch (fourth- and fifth-generation) and finally to self-etch (sixth-, seventh-, and eighth-generation) systems. ${ }^{2}$

However in the midst, other important issues concerning the biocompatibility of composite resins-though at times briefly acknowledged-have gone otherwise largely unaddressed. ${ }^{5,6}$ As can be expected of any synthetic material placed within a biological system, composite restorations are not completely inert. ${ }^{7-9}$ They interact dynamically with the host, forces, and conditions present in the oral environment. ${ }^{1,8,10}$ By the early 1990 s, investigations into the durability of resin-based restorative materials in vivo were reporting material loss at a faster rate than could attribute purely to mechanical forces. ${ }^{11,12}$ Others had found material discoloration at the tooth-composite marginal interface, ${ }^{13,14}$ a clear marker of degradation at the adhesive-dentin interface over time. ${ }^{14,15}$ Release of toxic products from composite restorations such as methacrylic acid and formaldehyde, ${ }^{9,11,16}$ and other leachable by-products were also being detected. ${ }^{17,18}$

These early findings attested to the fact that resin-based dental materials are indeed subject to chemical degradation in
${ }^{1-3}$ Department of Conservative Dentistry and Endodontics, MA Rangoonwala Dental College and Research Centre, Pune, Maharashtra, India

Corresponding Author: Asiya Mujawar, Department of Conservative Dentistry and Endodontics, MA Rangoonwala Dental College and Research Centre, Pune, Maharashtra, India, Phone: +91 202643515, e-mail: drasiyashaikh786@gmail.com

How to cite this article: Mujawar A, Hegde V, Shanmugasundaram S. A Microleakage Evaluation of Two Generations of Bonding Agents Using a Novel Fluid Filtration Model. Int J Prosthodont Restor Dent 2020;10(1):21-25.

Source of support: Nil

Conflict of interest: None

the oral cavity., ${ }^{719}$ Polymers of resin-based composites are bound by unprotected ester linkages inherently prone to cleavage by water. $17,19,20$

Since the composition of human saliva is nearly $99 \%$ water, these materials are highly susceptible to hydrolytic degradation in vivo. More importantly, saliva also contains esterase-like enzyme activities capable of accelerating the hydrolytic process and, thus, the rate of chemical degradation. . $^{6,920-23}$

Very little research has focused on the impact of biodegradation along the tooth-resin interface. Of particular concern are proximal and cervical restorations where the cavosurface margin is formed against wet dentinal substrate. ${ }^{24}$ Under optimal bonding conditions, resin penetration of cut tubules and associated branches results in the formation of resin tags that provide mechanical interlocks, fusing the hybrid layer to the un-etched dentinal substrate below. ${ }^{25}$

Over the past years, microleakage studies determining the leakage of bonding agents have been published; however,

() The Author(s). 2020 Open Access This article is distributed under the terms of the Creative Commons Attribution 4.0 International License (https://creativecommons. org/licenses/by-nc/4.0/), which permits unrestricted use, distribution, and non-commercial reproduction in any medium, provided you give appropriate credit to the original author(s) and the source, provide a link to the Creative Commons license, and indicate if changes were made. The Creative Commons Public Domain Dedication waiver (http://creativecommons.org/publicdomain/zero/1.0/) applies to the data made available in this article, unless otherwise stated. 
the methods used are varied and most of them present an nonstandardized method of microleakage evaluation. There are various methods to measure microleakage including chemical, bacterial and radioactive tracers, dye penetration, dye extraction, electrochemical, neutron activation, and micro-computed tomography; however, they present inherent drawbacks. ${ }^{5}$

The fluid filtration method has been widely used to measure microleakage., ${ }^{1,4}$ This method has several advantages over the commonly used methods: the samples are not destroyed, permits the evaluation of microleakage over time, operators bias, and most importantly the results are accurate since very small volume is recorded.

Hence, this study is aimed at evaluating microleakage of two different generations of bonding using the fluid filtration method.

\section{Materials and Methods}

In total, 60 human extracted mandibular molars were used in the study. The teeth were cleaned by ultrasonic scaler and were washed thoroughly before being stored in normal saline solution at room temperature. Following which the teeth were mounted on acrylic block and standard class I cavity preparation of approximately $1.5 \mathrm{~mm}$ depth and $3 \mathrm{~mm}$ width were prepared with airotor and diamond bur no. 330 (SS White FG). The teeth were randomly divided into three groups $(n=20)$ according to the bonding agent used as follows:

Group I: Adper Scotchbond primer and adhesive

Group II: Single Bond Universal

Group III: Control group

Positive control-specimens restored without bonding agents.

Negative control_-specimen restored with Adper Single Bond 2 (total-etch).

All the prepared cavities were rinsed with water from a syringe, for 30 seconds and dried with absorbent paper for 15 seconds, before the restoration of the cavities.

In group I, the cavities were etched using etchant (37\% phosphoric acid) for 15 seconds followed by rinsing for 15 seconds and air-dry for 5 seconds. Application of primer was done followed by gentle dry for 5 seconds. Adhesive application was done and was light cured for 10 seconds.

In group II, Single Bond Universal adhesive was applied in the cavities agitated using applicator tip followed by light curing for 20 seconds.

In the control group, in the positive control group, the teeth were not restored with bonding agent, and in the negative control group, the samples were etched with etchant ( $37 \%$ phosphoric acid), rinsed with water for 15 seconds, air-dried for 5 seconds, followed by application of Adper Single Bond 2, and light cured for 20 seconds.

All the samples were then filled with Filtex Z350 XT nanocomposite in incremental layering technique, and each increment was cured for 40 seconds. Using a diamond disk, dentin disks were prepared by sectioning the tooth, each measuring $6 \mathrm{~mm}$ in diameter and $2 \mathrm{~mm}$ in thickness.

The samples were then stored in distilled water for 24 hours followed by thermocycling in water bath for 1,000 cycles between $5 \pm 2^{\circ} \mathrm{C}$ and $55 \pm 2{ }^{\circ} \mathrm{C}$, for dwell time of 30 seconds and transfer time of 10 seconds.

The samples were then placed in the fluid filtration model to evaluate microleakage (Figs 1 and 2). The statistical analysis was done using independent student $t$ test to do intergroup comparison. The significant statistical difference was kept as $p<0.05$.

\section{Results}

The intergroup distribution of microleakage was presented in Table 1. Self-etch adhesives showed least leakage compared to the total-etch adhesives (Fig. 3).

The intergroup statistical comparison of group I with control was presented in Table 2. The comparison of the group I with the positive controls showed that there was a decrease in the microleakage of group I compared to the positive control, which was found to be statistically significant $(p<0.005)$. Group I also showed less leakage compared to the negative controls, which was statistically significant $(p<0.005)$.

The intergroup statistical comparison of group II with control was presented in Table 3. The findings of group II were significantly lower compared to the positive controls, i.e., the controls showed more amount of microleakage, and this was found to be statistically significant $(p<0.005)$. Also, the group II observations were less than the negative control which was also found to be statistically significant $(p<0.005)$.

The intergroup statistical comparison of group I and group II with the positive and negative controls was presented in Table 4. The mean of the positive controls was higher than that of the group I and group II, and this difference was statistically significant. The mean of the negative control was lower than that of the mean score of group I and group II, and this difference was found to be statistically significant. When all the groups were compared using analysis of variance, the scores of the positive control were significantly higher than those of the two intervention groups as well as the negative controls.

\section{Discussion}

The success of any restorative therapy is to provide an absolute seal in order to prevent the further deterioration of the existing dental disease and prevent it from reaching the pulp. Microleakage of dental materials, especially composites, is the most important factor that affects the outcome of the treatment provided. It is a wellknown and a well-established fact that the amount of microleakage and the failure rate are directly proportional to each other. It thus reduces the shelf life of the restoration, and hence, understanding the extent of its existence among the present materials being used on patients currently is essential for a more improved and long-term treatment. ${ }^{28}$

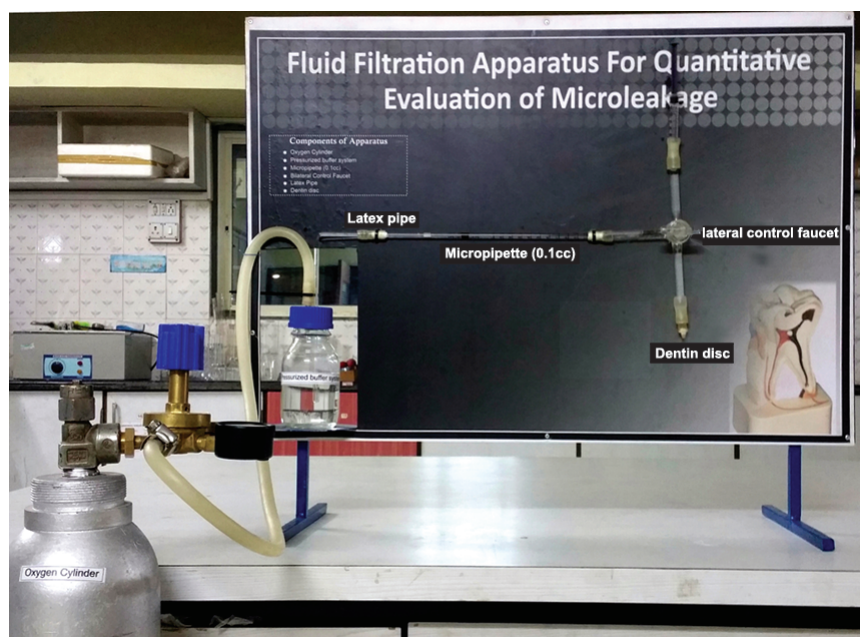

Fig. 1: Specimen testing using fluid filtration model 

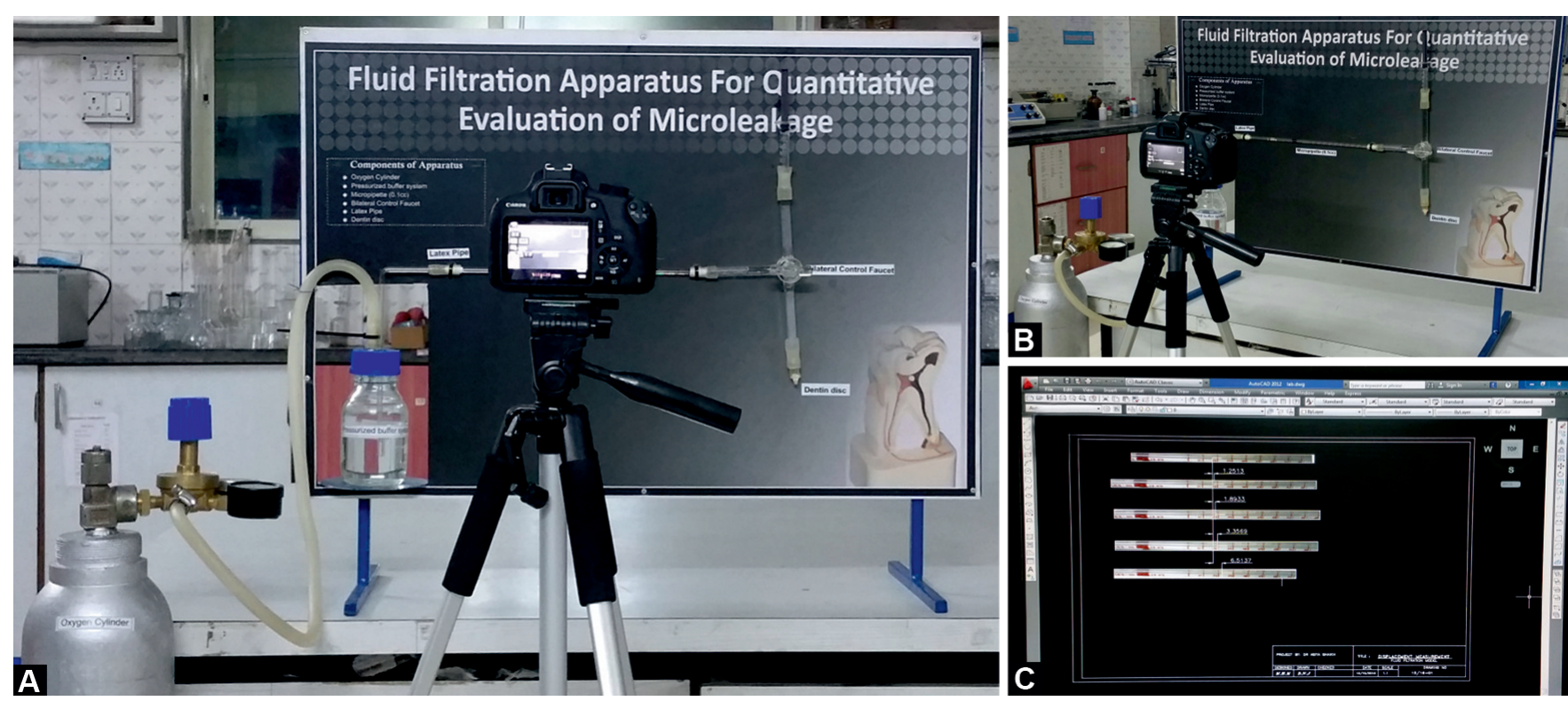

Figs $2 A$ to $C$ : (A)Fluid filtration model with recorder system; (B) Lateral view; (C) AutoCAD

Table 1: Intergroup distribution of microleakage

\begin{tabular}{|c|c|c|c|c|c|c|c|c|}
\hline & & & & & \multicolumn{4}{|c|}{ Group III } \\
\hline & \multicolumn{2}{|c|}{ Group I } & \multicolumn{2}{|c|}{ Group II } & \multicolumn{2}{|c|}{ Positive control } & \multicolumn{2}{|c|}{ Negative control } \\
\hline & Mean & $S D$ & Mean & $S D$ & Mean & $S D$ & Mean & $S D$ \\
\hline $\begin{array}{l}\text { Microleakage } \\
\left(\mu \mathrm{L} / \text { minute/cm H} \mathrm{H}_{2} \mathrm{O}\right)\end{array}$ & 3.265 & \pm 0.771 & 1.360 & \pm 0.305 & 5.642 & +0.30672 & 1.079 & +0.553723758 \\
\hline
\end{tabular}

$\mathrm{SD}$, standard deviation

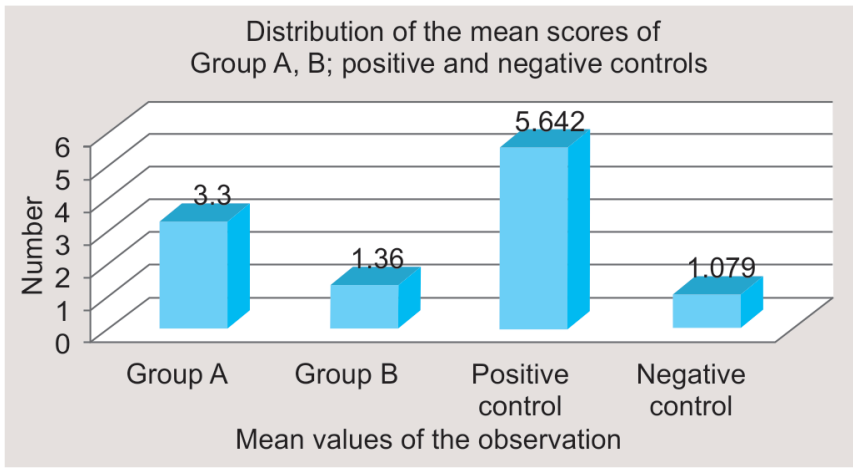

Fig. 3: Intergroup distribution of microleakage

The dental literature supports the use of tooth bonding adhesives when used according to the manufacturer's instruction unique for each product, as being effective in enhancing retention of restorations, minimizing microleakage, and reducing sensitivity. ${ }^{29}$ Microleakage at tooth dental restoration interface is the main factor affecting longevity, in which restorative margins could be colored or it might lead to secondary caries, increased sensitivity in the restored tooth, and also pulp.

In the present study, we used 60 extracted human mandibular molar teeth that were randomly divided into two groups for ease of comparison between the two types of restorative materials, i.e., group I: Adper Scotchbond primer and adhesive and group II: Single Bond Universal.
Table 2: The intergroup statistical comparison of group I with control

\begin{tabular}{llll}
\hline Group & $t$ value & $p$ value & Significance \\
\hline Group I with positive controls & 9.163 & $<0.005$ & Significant \\
Group I with negative controls & 7.92 & $<0.005$ & Significant \\
\hline
\end{tabular}

Table 3: The intergroup statistical comparison of group II with control

\begin{tabular}{llll}
\hline Group & $t$ value & $p$ value & Significance \\
\hline Group II with positive controls & 33.73 & $<0.005$ & Significant \\
Group II with negative controls & 0.043415 & $<0.005$ & Significant \\
\hline
\end{tabular}

Table 4: Intergroup statistical comparison of group I and group II with the positive and negative controls

\begin{tabular}{llll}
\hline Group & Fvalue & $p$ value & Significance \\
\hline Group I & 127.98 & $<0.0001$ & Significant \\
Group II & 495.02 & $<0.0001$ & Significant \\
All the groups & 168.55 & $<0.0001$ & Significant \\
\hline
\end{tabular}

The present study used two materials (i.e., Adper Scotchbond primer and adhesive and Single Bond Universal adhesive) that are routinely used in clinical settings and are found to be equally successful on the clinical evaluation for the long run by practitioners. Although enamel adhesion is a predictable and established entity, an adequate bond to dentin is more difficult to achieve. To overcome this challenge, technological advancements of dentin adhesives have, at this time, evolved into two trends: total acid-etching techniques. ${ }^{30}$ 
The concept of total-etch adhesion for enamel and dentin is well accepted. Although new techniques with self-etching adhesives have been introduced, there is a need for more clinical trials before making a complete switch to these systems. Currently, the adhesive considered as gold standard are total-etch systems. ${ }^{31}$ In this study, a total-etch adhesive, i.e., Adper Single Bond 2 is used as a positive control, since studies have reported a superior adhesion of totaletch adhesive over self-etch. Hence, in order to compare multiplestep bonding adhesive over single step, total-etch adhesive is used as a control.

In this study, self-etch adhesive systems had the best performance. The utilization of these adhesives on dentin does not alter the microleakage values. In another study, the authors reported that there was no difference between the Scotchbond Multipurpose and the Adper Scotchbond, which is contrast to the findings of the present study. Even though they report of microleakage while using the two materials, there was no significant difference unlike the present study findings.

The current procedure was carried out using the fluid filtration technique. There are various studies that have been carried out similarly using the same technique, but a direct comparison cannot be made since there is a change in the methodology design, and also the exact location and amount of microleakage cannot be always accurately determined clinically. We used this technique because it is not destructive in nature. It also allows the samples to be investigated over a period of time regarding the leakage. It provides some level of qualitative and quantitative analysis since the photographs can be used as a record for further future evaluation. ${ }^{32}$

Pashley et al. found no correlation between the bonds to enamel of these adhesive systems and their $\mathrm{pH}$ (weak, moderate or strong). So far, the literature does not provide a straightforward answer whether mild self-etch adhesives bonded to enamel can withstand the mechanical and chemical challenges of the oral cavity. ${ }^{33}$

In addition, Munoz et al., ${ }^{34}$ found using universal bonding with the self-etch approach that nanoleakage level was similar to Clearfil SE Bond, which is the gold standard of self-etch adhesives. They concentrated on instant characteristics of universal adhesives to dentin, including bond strength, nanoleakage, and conversion degree of Clearfil SE Bond, Adper Single Bond, Peak Universal Adhesive, Scotchbond Universal, and All-Bond Universal. They suggested that Scotchbond Universal showed the lowest microleakage between the seventh-generation universal adhesives.

However, other techniques like the dye penetration method according to Taylor and Lynch are destructive method. It also fails to demonstrate the nature and pattern of leakage. Also the technique has other disadvantages like size of the dye, the type of dye, and also its cross-reaction of the dentin. ${ }^{29}$ The other techniques such as three-dimensional micro-computed tomography, bacterial microleakage, and use of metal based like silver nitrate have not been that successful since long-term assessment of the specimens is not possible by using these techniques.

Also a study by Rueggeberg proved that the time after extraction does not have any effect on the bonding of the material to the teeth. It may vary from a few minutes to a few years also. ${ }^{35}$ Hence, we used the freshly extracted molars for the study purpose to avoid biological bias in the study.

The evaluation of microleakage is performed by different methods, such as air pressure, bacterial assessment, radioisotope studies, scanning electron microscopy, chemical identifiers, electrochemical studies, and measurement of dye penetration. ${ }^{36}$ Some studies have reported that different methods of microleakage evaluation do not differ in the final results. ${ }^{37}$

The result of the current study are consistent with study carried out by Pradelle et al., ${ }^{38}$ the study stated that etch and rinse and self etch systems do not differ in dentin margin microleakage.

In fluid filtration method of this study, the microleakage of self-etch adhesive was more significantly than total-etch adhesive. In contrast to our finding, it was indicated that Xeno III self-etch adhesive had less leakage than Prime and Bond NT total-etch adhesive using fluid filtration. ${ }^{39}$ This difference may be referred to the different self-etch and total-etch adhesives used in these studies and the laboratory assembly. Incomplete bonded restorations may produce changes in fluid flow and microleakage. In the present study, more microleakage was observed in the self-etch adhesive than in the total-etch adhesive that is in agreement with those of Loguercio et al.'s study. ${ }^{37}$

One explanation for microleakage is the degree of conversion that is not occurred completely in self-etch adhesives due to the existence of water and more hydrophilic monomers in their contents. ${ }^{40}$

Previous studies have evaluated the correlations among the three methods of microleakage assessment, fluid filtration method was defined as the control group and the correlations of the two other methods were assessed by it. Therefore, the study was not indicated any significant correlations between the qualitative method (dye penetration) and quantitative methods (fluid filtration and dye extraction) like the past paper, but there was a positive correlation between them. ${ }^{41}$

This finding may be due the different test setup and separate samples prepared for each microleakage assessment method. Additionally, it is advisable to use fluid filtration methods instead of dye extraction in order to get reliable quantitative results. In the future, it would be advisable to assess the sealing ability of different adhesives with various methods and handling techniques for a long time and even in a in situ study.

\section{Conclusion}

Within the limitations of this in vitro study, it can be concluded that the single-step adhesive provided definite edge over multistep approach of adhesives. However, when comparing with the results of previous literature, it does not provide a straightforward answer to whether self-etch or etch and rinse adhesive; hence, more studies need to be emphasized in future.

\section{RefERENCES}

1. Van Noort R. Introduction to Dental Materials. Papel. Spain: Times Mirror International Publishers Limited; 1994. pp. 3-145.

2. El-Mowafy OM, Lewis DW, Benmergui C, et al. Meta-analysis on longterm clinical performance of posterior composite restorations. J Dent 1994;22(1):33-43. DOI: 10.1016/0300-5712(94)90143-0.

3. Taylor DF, Bayne SC, Leinfelder KF, et al. Pooling of long-term clinical wear data for posterior composites. Am J Dent 1994;7(3): 167-174.

4. Turssi CP, De Moraes Purquerio B, Serra MC. Wear of dental resin composites: insights into underlying processes and assessment methods - a review. J Biomed Mater Res B Appl Biomater 2003;65(2):280-285. DOI: 10.1002/jbm.b.10563.

5. Finer Y, Jaffer F, Santerre JP. Mutual influence of cholesterol esterase and psuedocholinesterase on the biodegradation of dental 
composites. Biomaterials 2004;25(10):1787-1793. DOI: 10.1016/ j.biomaterials.2003.08.029.

6. Lin BA, Jaffer F, Duff MD, et al. Identifying enzyme activities within human saliva which are relevant to dental resin composite biodegradation. Biomaterials 2005;26(20):4259-4264. DOI: 10.1016/j. biomaterials.2004.11.001.

7. Gopferich A. Mechanisms of polymer degradation and erosion. Biomaterials 1996;17(2):103-114. DOI: 10.1016/0142-9612(96)85755-3.

8. Schedle A, Franz A, Rausch-Fan X, et al. Cytotoxic effects of dental composites, adhesive substances, compomers and cements. Dent Mater 1997;14(6):429-440. DOI: 10.1016/S0300-5712(99)00018-4.

9. Santerre JP, Shajii L, Tsang H. Biodegradation of commercial dental composites by cholesterol esterase. J Dent Res 1999;78(8):1459-1468. DOI: $10.1177 / 00220345990780081201$

10. Wataha JC. Principles of biocompatibility for dental practitioners. $J$ Prosthet Dent 2011;86(2):203-209. DOI: 10.1067/mpr.2001.117056.

11. Freund M, Munksgarrd EC. Enzymatic degradation of BISGMA/ TEGDMA-polymers causing decreased microhardness and greater wear in vitro. Scand J Dent Res 1990;98(4):351-355. DOI: 10.1111/j.16000722.1990.tb00984.x.

12. Munksgaard EC, Freund M. Enzymatic hydrolysis of (di) methacrylates and their polymers. Scand J Dent Res 1990;98(3):351-355. DOI: 10.1111/j.1600-0722.1990.tb00971.x.

13. Asmussen E, Munksgaard EC. Bonding of restorative resins to dentine: status of dentine adhesives and impact on cavity design and filling techniques. Int Dent J 1988;38(2):97-104.

14. Prati $C$, Nucci $C$, Davidson $C L$, et al. Early marginal leakage and shear bond strength of adhesive restorative systems. Dent Mater 1990;6(3):195-200. DOI: 10.1016/0109-5641(90) 90029-E.

15. Lee SY, Greener EH, Mueller HJ. Effect of food and oral simulating fluids on structure of adhesive composite systems. J Dent 1995;23(1):27-35. DOI: 10.1016/0300-5712(95)90657-4.

16. Oysaed H, Sjovik-Kleven IJ. Release of formaldehyde from dental composites. J Dent Res 1988;67(10):1289-1294. DOI: 10.1177/00220345880670100901.

17. Bean TA, Zhuang WC, Tong PY, et al. Effect of esterase on methacrylates and methacrylate polymers in an enzyme simulator for biodurability and biocompatibility testing. J Biomed Mat Res 1994;28(1):59-63. DOI: 10.1002/jbm.820280108.

18. Shajii L, Santerre JP. Effect of filler content on the profile of released biodegradation products in micro-filled bis-GMA/TEGDMA dental composite resins. Biomaterials 1999;20(20):1897-1908. DOI: 10.1016/ S0142-9612(99)00087-3.

19. Coury AJ, Levy RJ, McMillin CR, et al. Degradation of materials in the biological environment. In: Ratner BD, Hoffman AS, Schoen FJ, et al. Biomaterials science: an introduction to materials in medicine. San diego, California: Academic Press Inc.; 1996. pp. 243-281.

20. Santerre JP, Shajii L, Leung BW. Relation of dental composite formulations to their degradation and the release of hydrolyzed polymeric-resin-derived products. Crit Rev Oral Biol Med 2001;12(2):136-151. DOI: 10.1177/10454411010120020401.

21. Finer $Y$, Santerre JP. The influence of resin chemistry on a dental composites biodegradation. J Biomed Mater Res 2004;69(2):233-246. DOI: $10.1002 / j b m . a .30000$.

22. Jaffer F, Finer $Y$, Santerre JP. Interactions between resin monomers and commercial composite resins with human saliva derived esterases. Biomaterials 2002;23(7):1707-1719. DOI: 10.1016/S01429612(01)00298-8.
23. Finer $Y$, Santerre JP. Salivary esterase activity and its association with the biodegradation of dental composites. J Dent Res 2004;83(1): 22-26. DOI: 10.1177/154405910408300105.

24. Buonocore MG, Matsui A, Gwinnett AJ. Penetration of resin dental materials into enamel surfaces with reference to bonding. Arch Oral Biol 1968;13(1):61-70. DOI: 10.1016/0003-9969(68)90037-X.

25. Eick JD, Robinson SJ, Byerley TJ, et al. Scanning transmission electron microscopy/energy-dispersive spectroscopy analysis of the dentin adhesive interface using a labeled 2-hydroxythelmethacrylate analogue. J Dent Res 1995;74(6):1246-1252. DOI: 10.1177/ 00220345950740060201.

26. Kaya S, Özer SY, Adigüzel O, et al. Comparison of apical microleakage of dualcuring resin cements with fluid-filtration and dye extraction techniques. comparison of apical microleakage. Med Sci Monit 2015;21:937-944. DOI: 10.12659/MSM.892741.

27. Van Meerbeek B, De Munck J, Yoshida Y, et al. Adhesion to enamel and dentin: current status and future challenges. Oper Dent 2003;28(3):550-555.

28. Youngson CC. In vitro marginal leakage: examination of measurements used in assessment. J Dent 1990;18(1):142-146. DOI: 10.1016/03005712(90)90053-H.

29. Taylor MJ, Lynch E. Marginal adaptation. J Dent 1992;20(1):3-10. DOI: 10.1016/0300-5712(92)90002-T.

30. Kallenos TN, Al-Badawi E, White GE. An in vitro evaluation of microleakage in class I preparations using 5 th, 6 th, and 7 th generation composite bonding agents. J Clin Pediatr Dent 2005;29(4):323-328. DOI: 10.17796/jcpd.29.4.b51q018j100403p5.

31. Jain P, Belcher M. Microleakage of class II resin based composite restorations with flowable composite in the proximal box. Am J Dent 2001;13(5):235-238.

32. Phillips RW. Phillip's science of dental materials. 10th ed., Philadelphia PA: W.B. Saunders Co; 1996. pp. 243-280.

33. Pashley DH, Tay FR. Aggressiveness of contemporary selfetching adhesives. Part II: Etching effects on unground enamel. Dent Mater 2001;17(5):430-444.

34. Muñoz MA, Luque I, Hass V, et al. Immediate bonding properties of universal adhesives to dentine. J Dent 2013;41(5):404-411. DOI: 10.1016/j.jdent.2013.03.001.

35. Rueggeberg FA. Substrate for adhesion testing to tooth structure-a review of literature. Dent Mater 1991;7:2-10.

36. Gregoire G, Guignes PH, Millas A. Effect of self-etching adhesives and dentin permeability in a fluid flow model. J Prosthetc Dent 2005;93:56-63. DOI: 10.1016/j.prosdent.2004.10.008.

37. Loguercio AD, Bittencourt DD, Baratieri LN, et al. A 36-month evaluation of self-etch and etch-and-rinse adhesives in non-carious cervical lesions. J Am Dent Assoc 2007;138(4):507-514. DOI: 10.14219/ jada.archive.2007.0204.

38. Pradelle-Plasse N, Wenger F, Picard B, et al. Evaluation of microleakage of composite resin restorations by an electrochemical technique: the impedance methodology. Dental Mater 2004;20(5):425-434. DOI: 10.1016/j.dental.2003.06.003.

39. Deliperi S, Bardwell DN, Wegley C. Xeno III self-etch adhesive had less leakage than Prime and Bond NT total-etch adhesive using fluid filtration. Oper Dent 2007;32(2):179-184.

40. Bracket WW, Haisch LD, Pearce MG, et al. Microleakage of class V resin composite restorations placed with self-etching adhesives. J Prosthet Dent 2004;91(1):42-45. DOI: 10.1016/j.prosdent.2003.10.003.

41. Camps J, Pashley D. Reliability of the dye penetration studies.J Endod 2003;29(9):592-594. DOI: 10.1097/00004770-200309000-00012. 